\title{
REVIEW
}

\section{Role of Matrix Metalloproteinases and Therapeutic Benefits of Their Inhibition in Spinal Cord Injury}

\author{
Haoqian Zhang, ${ }^{1}$ Mayland Chang, ${ }^{4}$ Christopher N. Hansen, ${ }^{5}$ D. Michele Basso, ${ }^{5,6}$ and \\ Linda J. Noble-Haeusslein ${ }^{1,2,3}$
}

${ }^{I}$ Department of Neurosurgery, University of California, 513 Parnassus Avenue, Room HSE 722, San Francisco, California 941430110; ${ }^{2}$ Department of Anatomy, and ${ }^{3}$ Department of Physical Therapy and Rehabilitation Science, University of California, San Francisco, California 94143; ${ }^{4}$ Department of Chemistry and Biochemistry, University of Notre Dame, Notre Dame, Indiana 46556; ${ }^{5}$ Neuroscience Graduate Studies Program; and ${ }^{6}$ School of Allied Medical Professions, The Ohio State University, Columbus, Ohio 43210

Summary: This review will focus on matrix metalloproteinases (MMPs) and their inhibitors in the context of spinal cord injury (SCI). MMPs have a specific cellular and temporal pattern of expression in the injured spinal cord. Here we consider their diverse functions in the acutely injured cord and during wound healing. Excessive activity of MMPs, and in particular gelatinase B (MMP-9), in the acutely injured cord contributes to disruption of the blood-spinal cord barrier, and the influx of leukocytes into the injured cord, as well as apoptosis. MMP-9 and MMP-2 regulate inflammation and neuropathic pain after peripheral nerve injury and may contribute to SCI-induced pain. Early pharmacologic inhibition of MMPs or the gelatinases (MMP-2 and MMP-9) results in an improvement in long-term neurological recovery and is associated with reduced glial scarring and neuropathic pain. During wound healing, gelatinase A (MMP-2) plays a critical role in limiting the formation of an inhibitory glial scar, and mice that are genetically deficient in this protease showed impaired recovery. Together, these findings illustrate complex, temporally distinct roles of MMPs in SCIs. As early gelatinase activity is detrimental, there is an emerging interest in developing gelatinase-targeted therapeutics that would be specifically tailored to the acute injured spinal cord. Thus, we focus this review on the development of selective gelatinase inhibitors. Key Words: Spinal cord injury, matrix metalloproteinases, neuropathic pain, recovery, therapeutics.

\section{INTRODUCTION}

Matrix metalloproteinases (MMPs) are involved in a wide range of proteolytic events requiring matrix remodeling in normal development, wound healing, and repair throughout life $[1,2]$. In brain and spinal cord injuries, MMPs have been shown to degrade components of the basal lamina, leading to disruption of the blood-brain barrier (BBB) [3-5], and to contribute to oxidative stress [6], demyelination [4], leukocyte trafficking, and a progressive

Haoqian Zhang and Mayland Chang, contributed equally to this review.

Electronic supplementary material The online version of this article (doi:10.1007/s13311-011-0038-0) contains supplementary material, which is available to authorized users.

Address correspondence and reprint requests to: Haoqian Zhang, Ph.D., Department of Neurosurgery, University of California, 513 Parnassus Avenue, Room HSE 722, San Francisco, CA 94143-0110. E-mail: Haoqian.Zhang@ucsf.edu. neuroinflammatory response $[3,4,7]$. In this review, we will focus on the roles of MMPs and the therapeutic implication of their inhibitors in spinal cord injury (SCI).

For the past decade, MMPs have been studied in a variety of neurodegenerative diseases, as well as in experimental models of central nervous system (CNS) trauma $[3,4,8]$. Studies of the latter have demonstrated that MMPs, expressed acutely after injury, are key mediators of pathogenesis. Their short-term blockade with either broad-spectrum MMP inhibitors or more specific gelatinase inhibitors is neuroprotective and results in neurologic recovery [5, 6]. Given these exciting findings, there is considerable interest in defining those MMPs that mediate early pathogenesis by establishing the therapeutic window for intervention and by developing more specific inhibitors for MMPs.

Here we provide a brief overview of MMPs and their regulation, we address their complex roles in both the acute and chronically injured spinal cord, and we 
consider the emergence of specific MMP inhibitors that will likely lead to a more complete understanding of the role of these proteases in the injured spinal cord and to the development of therapeutics that are specifically tailored to the patient with SCI.

\section{OVERVIEW OF THE BIOLOGY OF MMPS}

MMPs are best known for their ability to cleave constituents of the extracellular matrix (ECM). In more recent years, their targets have greatly expanded to include other proteinases, proteinase inhibitors, clotting factors, chemotactic molecules, latent growth factors, growth factor-binding proteins, cell surface receptors, cell-cell adhesion molecules, and almost all structural ECM proteins [9]. Processing of these molecules influences cell functions as diverse as cellular differentiation, migration, regulation of growth factor activity, survival or apoptosis, angiogenesis, inflammation, and signaling $[1,2]$.

\section{Classification and protein structure}

The MMPs constitute a family of both a zinc- and a calcium-dependent endopeptidase that includes 23 human (24 murine) MMP members [1]. Based on protein structure and substrate specificity, MMPs are divided into collagenases (MMP-1, MMP-8, MMP-13, and MMP18), gelatinases (MMP-2 and MMP-9), stromelysins (MMP-3, MMP-10, and -11), membrane-type MMPs (MMP-14 [MT1-MMP], MMP-15 [MT2-MMP], MMP16 [MT3-MMP], MMP-17 [MT4-MMP], MMP-24 [MT5-MMP], and MMP-25 [MT6-MMP]), and other MMPs $[1,2]$. In general, MMPs contain three structural domains: 1) the $N$-terminal propeptide domain, 2) an internal catalytic domain, and 3) a $C$-terminal hemopexin domain. MMPs are initially produced as inactive zymogens, with a cysteine residue at the propeptide region that binds the zinc ion present at the catalytic site. Activation requires removal of the propeptide domain to expose the active catalytic site. The transmembrane domain is found only in the membrane-type MMPs (MT-MMPs) and is linked to the plasma membrane either by a transmembrane domain or by a glycosylphosphatidylinositol linkage attached to the hemopexin domain.

\section{Modulation of MMPs}

MMPs are regulated by various mechanisms that include gene transcription, mRNA stability, translational control, zymogen activation via proteolysis, inhibition by endogenous inhibitors, and their localization [9]. MMPs are regulated at the transcriptional level and by posttranslational modification. Most MMPs are not constitutively expressed at detectable levels. Transcription of
MMP genes is thought to be mediated by intracellular signals in response to growth factors, cytokines, chemokines, and components of the ECM [9].

Post-translational modifications provide a second level of regulation. Although most MMPs are secreted as inactive zymogens, a subset of MMPs including MMP11, MMP-27, and the MT-MMPs are activated primarily intracellularly by serine proteases of the pro-protein convertase class such as furin [9]. Some MMPs are cleaved in their propeptide domains, by serine proteinases such as the uPA-plasmin system and trypsin. Activation of other pro-MMPs is mediated by already activated MMPs. For example, pro-MMP-7 is activated by MMP-3, and MMP-7 activates pro-MMP-1 and pro-MMP-9 [10]. MT1-MMP activates pro-MMP-13 and this activated MMP-13, which may then go on to activate MMP-9 [11, 12]. MMP-2 is activated at the cell surface through a unique and complex mechanism involving MMP-14 (MT1-MMP) and tissue inhibitors of matrix metalloproteinase (TIMP)-2 [9]. Indeed, the transmembrane MT-MMPs (MT1-MMP, MT2-MMP, MT3-MMP, and MT5-MMP) are all able to activate pro-MMP-2, except for MT4-MMP and human, but not mouse). MT2-MMP are the only MT-MMPs that are unable to activate MMP2 [9].

\section{Endogenous inhibitors of MMPs}

There are four known mammalian TIMPs: 1) TIMP-1,2) TIMP-2, 3) TIMP-3, and 4) TIMP-4. The $N$-terminal domain of TIMP proteins contains the MMP inhibitory domain, whereas the $C$-terminal domain of the TIMPs mediates important protein-protein interactions, in particular with the hemopexin domains of pro-MMPs [13]. Following activation, TIMPs modulate MMP activity by binding to the catalytic sites of MMPs, forming tight 1:1 noncovalent complexes $[9,13]$. The TIMPs differ in their affinity for specific MMPs, and their interaction does not always lead to inhibition. The latter is exemplified by TIMP-1, which binds pro-MMP-9, thus protecting this protease from MMP-3 cleavage.

\section{MMPS AND THE INJURED SPINAL CORD}

Here we profile those MMPs that have been studied in the injured spinal cord, focusing on their unique temporal and cellular profiles in the injured cord (Table 1).

\section{Time course and cellular localization}

One of the earliest studies of MMPs in SCI focused on the gelatinases MMP-9 and MMP-2 in the contused cords of rats [14]. Gelatin zymography revealed prominent MMP-9 activity by 12 - to $24-\mathrm{h}$ postinjury followed by a rise in MMP-2 by 5 days postinjury. These findings have since been confirmed in other species and models, 
including hemisection and compression. Zymography and Western blots revealed a transient increase in MMP-9 at 1day postinjury followed by a gradual rise in MMP-2, which then remained elevated for weeks thereafter [6, 15-18]. Although less studied, MMP-1 is also up regulated 1-day postinjury in a similar model of SCI; however, its time course has yet to be studied [18]. Together, these findings highlight a unique temporal profile for MMP-1, MMP-9, and MMP-2 in the injured cord, with the first and second dominating in the more acute phase, and the third associated with wound healing.

Several studies have profiled the expression of virtually all known MMPs after SCI by evaluation of mRNA transcripts. In a murine model of spinal cord compression, there is up-regulation of mRNA transcripts encoding MMP-9, MMP-3, MMP-7, MMP-10, MMP-11, MMP-13, MMP-19, and MMP-20 within $24 \mathrm{~h}$ of injury, whereas increased expression of MMP-2, MMP-12, and MMP-13 is delayed in onset until 5 days after injury [19]. A similar trend is reported in a spinal cord contusion model in the rat [20].

During their peak expression in the acutely injured spinal cord, both MMP-1 and MMP-9 are localized to neurons and glia [18]. In addition, MMP-9 is detected in blood vessels, neutrophils, and macrophages $[5,6,18]$. MMP-2 localizes to reactive astrocytes and neurons in the chronically injured cord [17, 20]. Finally, MMP-12 is expressed primarily in microglia/macrophages [19]. Similar to other MMPs, its temporal and cellular expression varies according to type and severity of injury.

\section{MMPS AND THEIR INHIBITORS IN INJURY AND RECOVERY PROCESSES}

SCI produces secondary tissue damage that continues to evolve days and weeks after the initial insult, accompanied by corresponding functional impairments. Reducing the extent of progressive tissue loss following SCI represents an essential step toward recovery after SCI. MMP inhibitors have been tested in several animal models of acute and chronic injury (Table 2). The overall impression is that early blockade of MMPs stabilizes the barrier, reducing apoptotic cell death, and confers both early and long-term neuroprotection.

\section{Inflammation and barrier breakdown}

Experimental models of SCI suggest that MMPs support infiltration of inflammatory cells into the injured cord and most likely contribute to early disruption of the blood-spinal cord barrier. As leukocytes transmigrate across the vascular wall, they release MMPs, which in turn degrades tight-junction related proteins and the surrounding basal lamina. Zonulae occludens-1, VEcadherin, and occludin are substrates for MMP-2, MMP-3, MMP-7, and MMP-9 [21-24]. Basal lamina proteins, such as fibronectin, laminin, and heparan sulfate, are also degraded by MMPs [25]. Involvement of MMPs in barrier disruption is supported by the finding that the broad-spectrum MMP inhibitor BB-3103 decreases endothelial gap formation and occludin loss [26].

Of the MMPs expressed by leukocytes, MMP-9, conveyed by infiltrating neutrophils, is a key mediator of early pathogenesis in the injured cord. Immunologically depleting neutrophils prior to SCI results in reduced MMP-9 activity in the injured cord, suggesting that these leukocytes are the principal source of this protease in the injured tissue [14]. In a murine model of spinal cord contusion injury, barrier disruption to the protein luciferase, is maximal at 24-h postinjury [27], a time point that corresponds to peak activity of MMP-9 [5]. Moreover, barrier disruption is reduced in MMP-9 null mice, as well as mice treated with the broad-spectrum MMP inhibitor GM6001 early during the maximal expression $3 \mathrm{~h}$ to 3 days after injury. Similar to findings with GM6001, intrathecal administration of the selective gelatinase inhibitor SB-3CT at $2 \mathrm{~h}$ before injury to the rat spinal cord reduces both MMP-9 activity and barrier disruption by 1-day postinjury and decreaes apoptotic cell death [6].

Similar findings supporting greater stabilization of the barrier have been reported in spinal cord injured MMP12 null mice [19]. MMP-12, also known as macrophage metalloelastase, is critical for the migration of bloodborne macrophages across the endothelial basement membranes into inflammatory sites [28]. Spinal cord injured MMP-12 null animals show attenuation of bloodspinal barrier breakdown. It is likely that MMP-12 also influences the migration of macrophages into the injured cord. Comparisons of cell density of Iba-1-positive elements reveal fewer macrophages and microglia in MMP-12 null mice compared with wild type animals [19].

\section{Oxidative stress and apoptosis}

Oxidative stress contributes to pathogenesis in the injured spinal cord [4]. MMPs are regulated by reactive oxygen species, including nitric oxide and hypochlorous acid $[29,30]$. Transgenic rats that over-express the antioxidant enzyme superoxide dismutase 1 (a crucial endogenous antioxidant enzyme responsible for eliminating superoxide) showed enhanced neuroprotection after SCI [31]. Active MMP-9 is increased at days 1, 3, and 7 after SCI in wild type rats, whereas there is no increase in the superoxide dismutase 1 transgenic rats. The end result is reduced disruption of the barrier and decreased apoptosis [6]. 


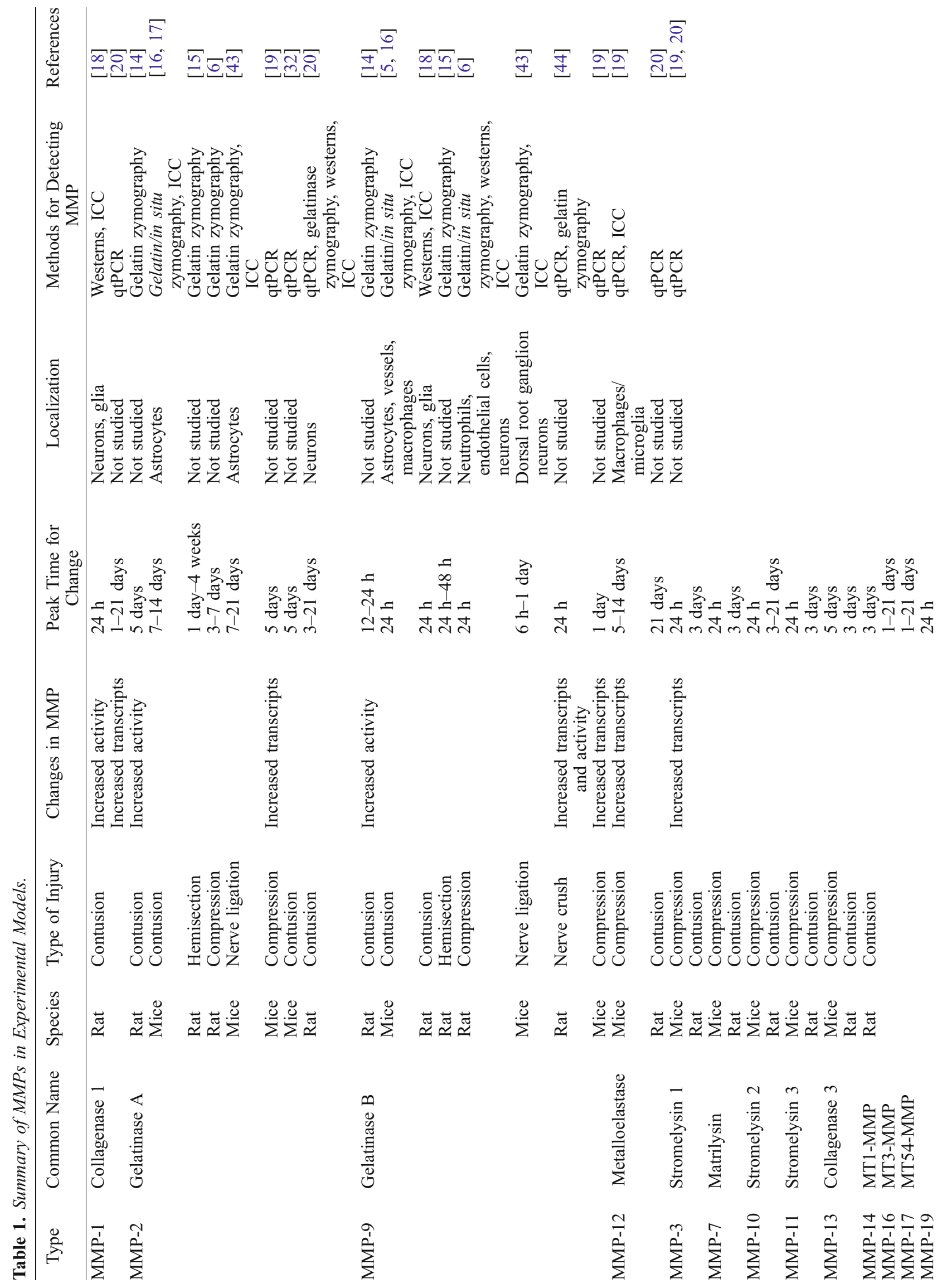



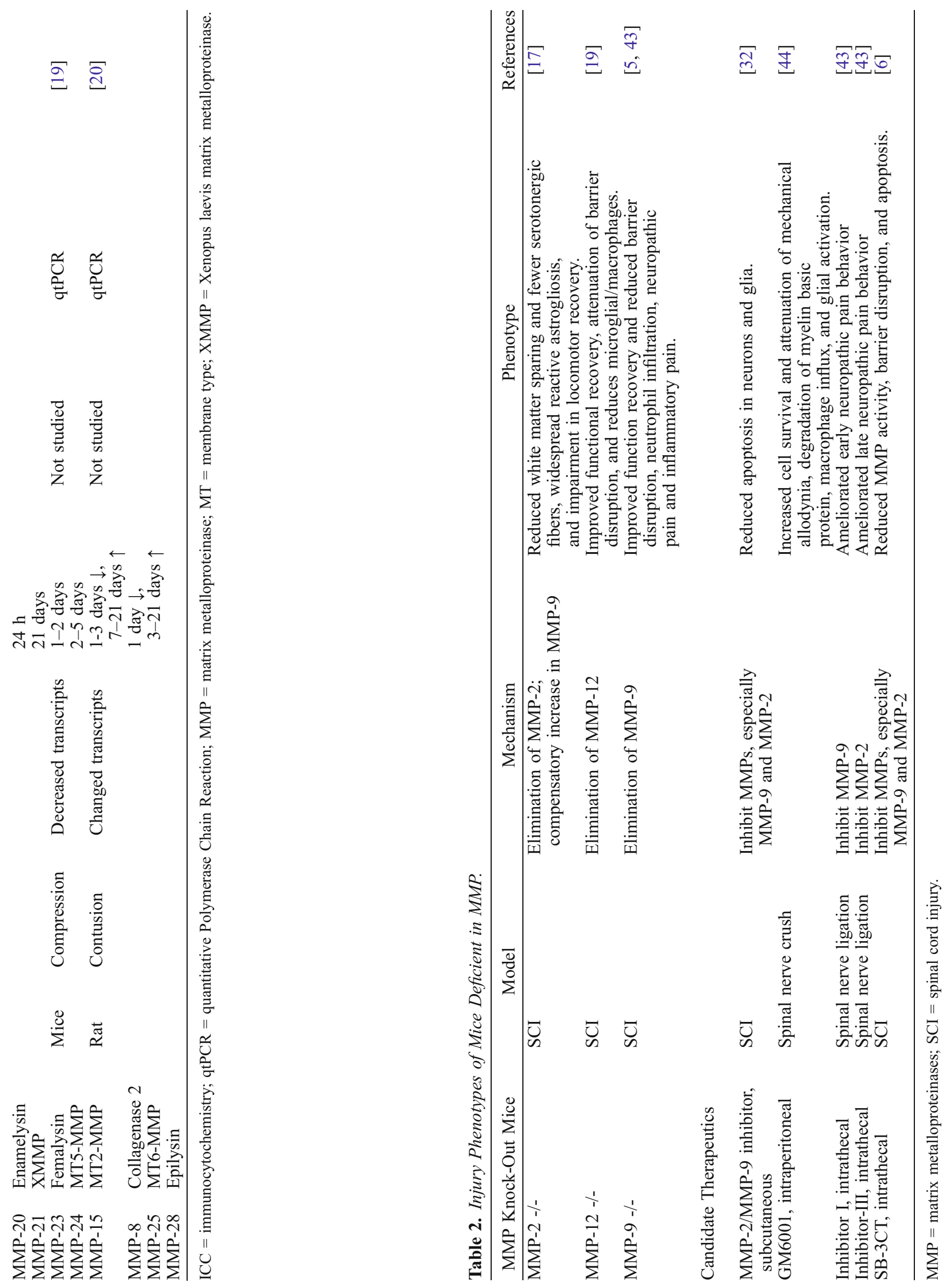
After SCI, MMP-2 contributes to apoptotic cell death, and is up-regulated along with neuronal and glial apoptosis. This temporal relationship raises a question as to whether or not MMP2 is a determinant of apoptosis after SCI [32]. Supporting this possibility, spinal cord injured mice, treated with an MMP-2/MMP-9 inhibitor delivered subcutaneously daily for 5 days, showed reduced levels of apoptosis in both neurons and glial [32]. Such a reduction in total cell death may contribute to long-term recovery.

Collectively, these studies provide strong evidence for pathological MMP-directed disruption of the blood-brain barrier, leukocyte infiltration, and cell apoptosis after SCI. Because early blockade of MMPs stabilizes the barrier, reduces leukocyte infiltration, and confers both early and long-term neuroprotection, it suggests that early inhibiton of MMPs may be an efficacious strategy for SCI.

\section{Glial scar formation}

Prolonged inhibition of MMPs, especially with broadspectrum inhibitors during wound healing can be detrimental to neurological recovery [33]. One reasonable explanation is that some MMPs, expressed during wound healing, are beneficial. There is growing literature to support this hypothesis. In the more chronically injured cord, MMPs are key regulators of the local microenvironment, degrading the ECM, and modulating the formation of an inhibitory glial scar [34].

After SCI, a variety of growth-inhibitory molecules are up-regulated [35]. A glial scar, an interface that is inhibitory to axonal regeneration, forms at the site of injury and is composed of reactive astrocytes, microglia/ macrophages, and ECM molecules, especially chondroitin sulfate proteoglycans (CSPGs) [35]. In response to injury, astrocytes, oligodendrocyte progenitors, and macrophages increase the expression of CSPGs, which in turn inhibit neurite outgrowth in vitro and regeneration in vivo $[36,37]$. MMPs degrade the core protein of some CSPGs, as well as other growth-inhibitory molecules, such as Nogo and tenascin-C [34]. CSPGs, such as neurocan and versican, are degraded by MMP-2, whereas tenascin-C, brevican, neurocan, NG2, phosphacan, and versican are degraded by MMP-3 [34]. By degrading CSPG and other inhibitory molecules, MMPs support axonal regenerative potential in the injured CNS $[2,34]$.

In a rat hemisection model, in situ zymography reveals MMP-related gelatinase activity in the injured site, which is spatially and temporally correlated with scar formation [15]. In vitro and in vivo data support the possibility that MMPs facilitate migration of astrocytes. In vitro scratch wound assays show attenuated migration of cultured MMP-9 null astrocytes or astrocytes treated with an MMP-9 inhibitor [38]. Moreover, in spinal cord injured
MMP-9 null mice, glial scar formation is abrogated along with reduced CSPG immunoreactivity at the lesioned epicenter [38].

The importance of MMP-2 in promoting functional recovery in the chronically injured spinal cord has been evaluated in MMP-2 deficient mice. MMP-2 null mice show greater CSPG immunoreactivity, fewer serotonergic fibers caudal to the injury site, and significantly reduced motor recovery compared with wild-type mice after a contusive SCI [17]. Such a finding may result from reduced sprouting across the lesioned site.

Finally, the complexity of MMPs in SCI is further realized in the context of axonal dieback. After SCI, infiltrated macrophages mediate long-distance axonal retraction from the initial site of injury. The involvement of MMPs in dieback is supported by in vitro studies showing that a broad-spectrum inhibitor or a specific MMP-9 inhibitor prevents macrophage-induced axonal retraction [39].

In summary, MMPs limit the formation of an inhibitory glial scar and degrade the inhibitory proteins, as well as cleave extracellular proteins that sequester growth factors $[34,40]$, thus supporting recovery processes. They also mediate adverse responses including axonal dieback.

\section{MMPS AND NEUROPATHIC PAIN}

Neuropathic pain manifests as an unpleasant somatosensory experience evoked by lesion or dysfunction in the nervous system and occurs in as many as $85 \%$ of SCI patients [41]. Types of neuropathic pain include: allodynia, which is a painful response to an innocuous stimulus; and hyperalgesia, which is an exaggerated pain response to a noxious stimulus. After SCI, neuropathic pain can be localized in dermatomes above, at, or below the level of injury. The complexities of neuropathic pain create a barrier for therapeutic intervention.

Peripheral nerve injury (PNI) models are perhaps the most common method of studying neuropathic pain, as mechanisms can be examined without direct damage to central pathways. Recent evidence shows that similar inflammatory mediators of pain exist for SCI and PNI [42], suggesting that PNI may help elucidate pain mechanisms after SCI. In PNI, MMPs appear to induce and maintain neuropathic pain, but a similar role after SCI is unknown [43-45]. Prominent similarities in cytokine profiles and microglial activation between SCI and peripheral injury make an MMP mechanism with at or below-level pain plausible [42].

\section{Neuropathic pain modulation in PNI}

The gelatinases (MMP-9 and MMP-2) appear to regulate neuropathic pain after PNI through degenerative 
and proinflammatory mechanisms. Nerve injury induces a rapid increase of active MMP-9 in the axon and dorsal root ganglia (DRG) by $24 \mathrm{~h}$. MMP-9 gene expression precedes and outlasts the active form [44, 45]. Active MMP-2 in the DRG is delayed until day 7 and persists through day 21 [43]. Although a distinct time course has not been described for gelatinase activity in the dorsal horn after PNI, an early MMP-9 and delayed MMP-2 pattern occurs [43]. A differential time course suggests distinct roles of MMP-9 and MMP-2 in the development and maintenance of neuropathic pain.

After mechanical damage to the axon, Schwann cells release MMP-9, initiating macrophage infiltration and degradation of myelin basic protein [44, 46]. Exposure of the bare axon leads to increased sodium channel expression and ectopic hyperexcitability of afferents [47]. As a result, action potentials outlast the stimulus creating central sensitization, a common mechanism of neuropathic pain.

Many proinflammatory cytokines and growth factors mediate gelatinase expression in the nervous system, potentially inducing neuropathic pain. Indeed, exposure of the uninjured peripheral nerve to nerve growth factor, tumor necrosis factor alpha or interleukin-1 beta (IL-1 $\beta$ ) induces robust MMP-9 expression by Schwann cells [45]. Although neuronal sensitization occurs with elevated cytokines alone [48], MMP-9 expression also appears to mediate pain behavior. Gene deletion of MMP-9 reduces nociceptive pain behavior after PNI $[43,45]$. In a proof-of-principle design, Kawasaki et al. [43] intrathecally injected MMP-9 and found marked allodynia accompanied by increased IL-1 $\beta$ cleavage and microglial activation in the dorsal horn co-localized with phosphorylated p38 MAP kinase. Blocking IL- $1 \beta$ signaling with a neutralizing antibody prevented allodynia, establishing IL-1 $\beta$ as a downstream regulator of neuropathic pain by reducing microglial activation and $\mathrm{p} 38$ levels. Normal expression and intrathecal injection of MMP-2 also cleaves IL-1 $\beta$ and activates spinal astrocytes at later time points, potentially maintaining neuropathic pain [43]. The distinct temporal activations of MMP-2 and MMP-9 provide novel opportunities for therapeutic intervention during different stages of allodynia.

\section{MMP inhibitors and neuropathic pain}

Outside of gene deletion, use of siRNAs and endogenous peptide inhibitors for general and specific inhibition of MMP-9 and MMP-2 effectively reduce allodynia after PNI. Daily systemic administration of a broad-spectrum gelatinase inhibitor (GM6001) $1 \mathrm{~h}$ to 12 days after PNI resulted in immediate and sustained attenuation of mechanical allodynia [44]. Cellular effects included preservation of myelin basic protein, little macrophage influx, and low glial activation in the dorsal horn [44]. Thus, relatively short-term inhibition of MMPs limited the behavioral and cellular sequella of central pain syndromes. However, an overabundance of cells occurred in the nerve, DRG, and dorsal horn after treatment with broad-spectrum MMP inhibitors due to reduced apoptosis [44]. Less apoptosis and increased cell density is not without risk, especially after SCI. Such side effects must be managed if broad-spectrum inhibitors are used to treat neuropathic pain.

Temporal profiles of MMP-9 and MMP-2 provide specific opportunities for treating neuropathic pain at different stages. Pretreatment with MMP-9 siRNA prevented the onset of allodynia for a maximum of 5 days. When MMP-2 siRNA was delivered late after PNI during pronounced MMP-2 activity, allodynia was attenuated for at least 1 day. Moreover, behavioral benefits were accompanied by reduced cleavage of IL$1 \beta$ with both types of siRNA and reduced microglial activation in the dorsal horn with MMP-9 siRNA [43]. Even greater reversal of allodynia occurred when endogenous inhibitors of MMP-9 (TIMP-1) and MMP-2 (TIMP-2) were administered during early or late phases of MMP activation after PNI, but the effect was transient, lasting only 3 to $24 \mathrm{~h}$ [43]. The largest and longest reduction in allodynia after PNI occurred with intrathecal injection of specific pharmacologic inhibitors timed to periods of high MMP activity. Inhibition of MMP-9 using Inhibitor-I (Calbiochem, Gibbstown, NJ), starting 2 days before and through 5 days after the injury, delayed the onset of allodynia for at least 6 days (Table 2). Using the synthetic MMP-2 inhibitor (Inhibitor-III, Calbiochem), allodynia was attenuated for a maximum of 10 days with daily intrathecal injections (Table 2) [43]. These results suggest that intrathecal delivery effectively reduces allodynia. Timing of the delivery and selection of the type of inhibitor will be critical to clinical success in treating neuropathic pain.

\section{Translation to SCI}

Marked similarity of behavioral and cellular mechanisms of neuropathic pain exists between PNI and SCI. Given the role of gelatinases in pain development and maintenance after PNI, examination of MMP-9 and MMP-2 with at and below-level pain after SCI is warranted. While a differential time course exists with MMP-9 and MMP-2 after both types of injury, the relevance of delivering broad-spectrum MMP inhibitors early is unclear, as SCI-induced neuropathic pain onset occurs months or years after injury. Perhaps broadspectrum inhibitors delivered at specific time points would be more effective for SCI, although serious musculoskeletal side effects may result from long-term 
Table 3. Competitive MMP Inhibitors.

\begin{tabular}{|c|c|c|c|c|c|c|c|c|c|c|}
\hline \multirow[t]{2}{*}{ No. } & \multirow[t]{2}{*}{ Structure } & \multirow[t]{2}{*}{ Other Name } & \multicolumn{6}{|c|}{$\mathrm{IC}_{50}(\mathrm{nM})$ or $* K_{\mathrm{i}}(\mathrm{nM})$} & \multirow[t]{2}{*}{ Indication/Comments } & \multirow[t]{2}{*}{ Ref. } \\
\hline & & & MMP-1 & MMP-2 & MMP-3 & MMP-7 & MMP-9 & MMP-14 & & \\
\hline 1 & & $\begin{array}{l}\text { Batimastat, } \\
\text { BB-94 }\end{array}$ & 3 & 4 & 20 & & 10 & 19 & $\begin{array}{l}\text { TACE: } \mathrm{IC}_{50}=>20,000 \mathrm{nM} \text {. } \\
\text { Cancer. Administered ip and } \\
\text { intrapleurally in clinical trials. } \\
\text { Produced musculoskeletal } \\
\text { (MSS) syndrome. Discontinued } \\
\text { after phase I (poor oral } \\
\text { bioavailability). }\end{array}$ & $(80)$ \\
\hline 2 & & $\begin{array}{l}\text { Marimastat, } \\
\text { BB-2516 }\end{array}$ & 0.78 & 0.41 & 14 & 4.1 & 0.79 & & $\begin{array}{l}\text { MMP-13: } \mathrm{IC}_{50}=1.2 \mathrm{nM} \\
\text { Cancer. Orally bioavailable. } \\
\text { Produced MSS. Discontinued } \\
\text { after phase III (lack of } \\
\text { efficacy). }\end{array}$ & (54) \\
\hline 3 & & $\begin{array}{l}\text { Ilomastat, } \\
\text { GM6001, } \\
\text { Galardin }{ }^{\circledR}\end{array}$ & $0.4^{*}$ & $0.5^{*}$ & $27^{*}$ & 3.7 & $0.2^{*}$ & $13.4^{*}$ & $\begin{array}{l}\text { Cancer, macular degeneration, } \\
\text { COPD. Discontinued after } \\
\text { phase I (poor oral } \\
\text { bioavailability). }\end{array}$ & (81) \\
\hline 4 & & $\begin{array}{l}\text { Rebimastat, } \\
\text { BMS-275291, } \\
\text { D-2163 }\end{array}$ & 9 & 39 & 157 & 23 & 27 & 40 & $\begin{array}{l}\text { Cancer. Musculoskeletal } \\
\text { toxicity. Discontinued after } \\
\text { phase III (poor response). }\end{array}$ & $(82)$ \\
\hline 5 & & $\begin{array}{l}\text { Tanomastat, } \\
\text { BAY 12-9566 }\end{array}$ & $>5,000^{*}$ & $11 *$ & $134 *$ & & $301 *$ & & $\begin{array}{l}\text { MMP-13: } K_{\mathrm{i}}=1,470 \mathrm{nM} \\
\text { Arthritis, cancer, kidney } \\
\text { transplant. Produced MSS, } \\
\text { hematological toxicity, } \\
\text { thrombocytopenia. } \\
\text { Discontinued Phase III (poor } \\
\text { survival rate). } \\
\end{array}$ & (83) \\
\hline 6 & & $\begin{array}{l}\text { Prinomastat, } \\
\text { AG-3340 }\end{array}$ & 5.7 & 0.048 & 3.5 & 72 & 0.048 & & $\begin{array}{l}\text { MMP-13: } \mathrm{IC}_{50}=0.2 \mathrm{nM} \\
\text { Cancer, macular degeneration. } \\
\text { Musculoskeletal toxicity. } \\
\text { Discontinued after phase III } \\
\text { (poor survival rate). }\end{array}$ & (54) \\
\hline 7 & & $\begin{array}{l}\text { Cipemastat, } \\
\text { Trocade } ®, \text { Ro- } \\
\text { 32-3555 }\end{array}$ & 1.77 & 3,420 & 694 & & 150 & 7.84 & $\begin{array}{l}\text { MMP-13: } \mathrm{IC}_{50}=7.28 \mathrm{nM} \\
\text { Rheumatoid arthritis, } \\
\text { osteoarthritis. Produced MSS. } \\
\text { Discontinued after phase II } \\
\text { (lack of efficacy). }\end{array}$ & (55) \\
\hline 8 & & $\begin{array}{l}\text { CGS-27023, } \\
\text { MMI-270 }\end{array}$ & $\begin{array}{l}* \\
15\end{array}$ & & $16^{*}$ & & $\begin{array}{l}3^{*} \\
9\end{array}$ & & $\begin{array}{l}\text { MMP- } 13: K_{\mathrm{i}}=5 \mathrm{nM} \\
\text { TACE: } K_{\mathrm{i}}=54 \mathrm{nM} \\
\text { Cancer. Oral bioavailability: } \\
\text { 44\% dog. Produced some MSS. } \\
\text { Discontinued after phase II. }\end{array}$ & (84) \\
\hline 9 & & MMI-166 & $>1,000$ & 0.4 & $>1,000$ & $>1,000$ & 90 & 100 & $\begin{array}{l}\text { MMP-8: } \mathrm{IC}_{50}=400 \mathrm{nM} \\
\text { Orally active in animal models } \\
\text { of tumor growth and } \\
\text { metastasis. }\end{array}$ & $(85)$ \\
\hline 10 & & Tolylsam & & 5 & 5,558 & & 49 & & $\begin{array}{l}\text { MMP-8: } \mathrm{IC}_{50}=397 \mathrm{nM} \\
\text { MMP-12: } \mathrm{IC}_{50}=34 \mathrm{nM} \\
\text { MMP-13: } \mathrm{IC}_{50}=201 \mathrm{nM}\end{array}$ & $(86)$ \\
\hline 11 & & FR255031 & 77.8 & 91.1 & $>10,000$ & & 3.94 & 1.80 & $\begin{array}{l}\text { MMP-13: } \mathrm{IC}_{50}=8 \mathrm{nM} \\
\text { TACE: } \mathrm{IC}_{50}=231 \mathrm{nM}\end{array}$ & (55) \\
\hline 12 & & RS-130830 & $\begin{array}{l}590^{*} \\
233\end{array}$ & $0.22 *$ & $9.3^{*}$ & & $\begin{array}{l}0.58^{*} \\
3\end{array}$ & & $\begin{array}{l}\text { MMP-13: } K_{\mathrm{i}}=0.52 \mathrm{nM} \text { TACE: } \\
K_{\mathrm{i}}=176 \mathrm{nM} \\
\text { Osteoarthritis. Discontinued } \\
\text { after phase I. }\end{array}$ & (84) \\
\hline 13 & & $\begin{array}{l}\text { SC-78080/SD- } \\
2590\end{array}$ & $>10,000$ & $<0.1$ & 28.7 & 7,000 & 0.18 & 13 & $\begin{array}{l}\text { MMP-13: } \mathrm{IC}_{50}=0.1 \mathrm{nM} \\
\text { Oral bioavailability } 52 \%-82 \% \text {. }\end{array}$ & (87) \\
\hline
\end{tabular}


Table 3. (Continued).

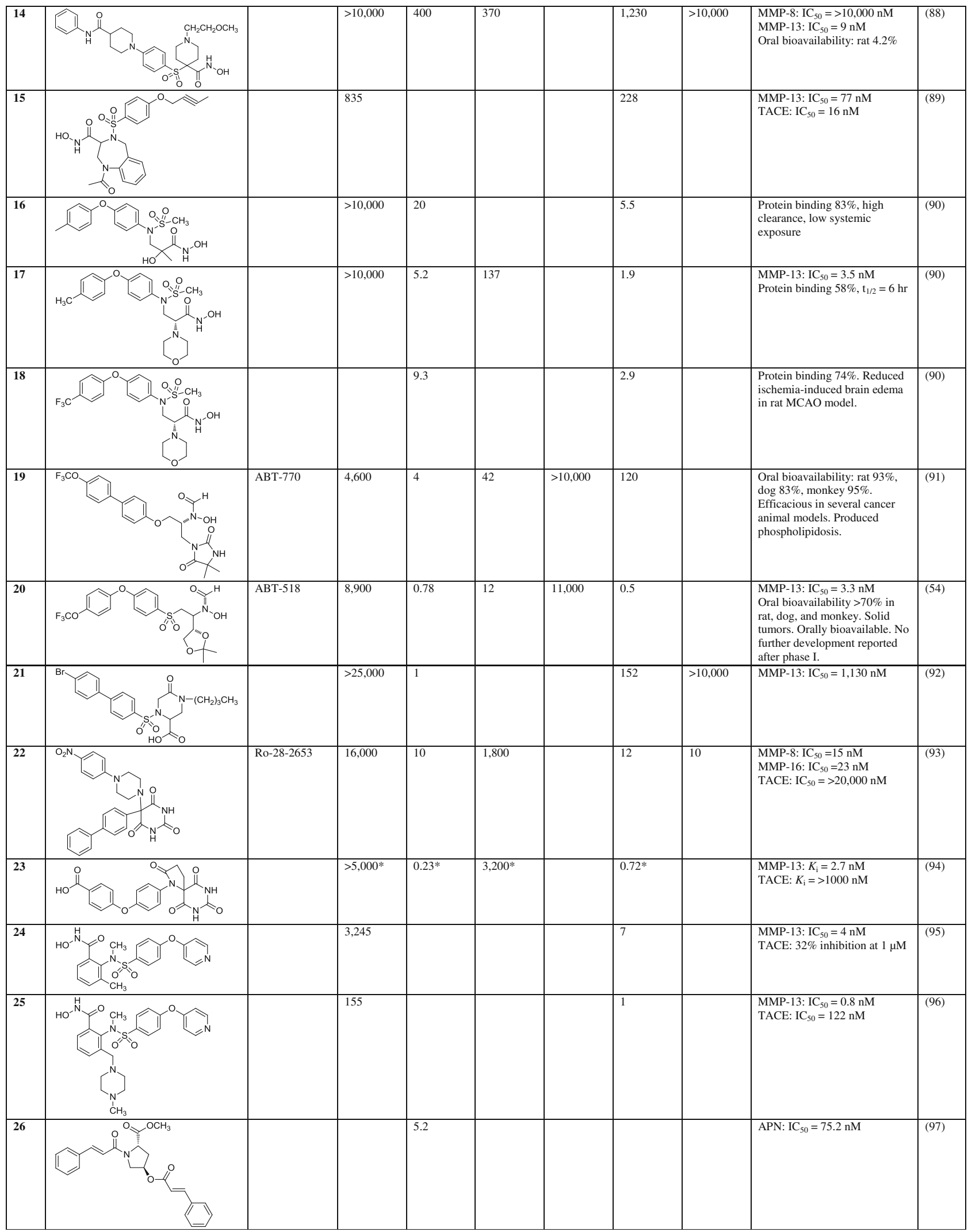


Table 3. (Continued).

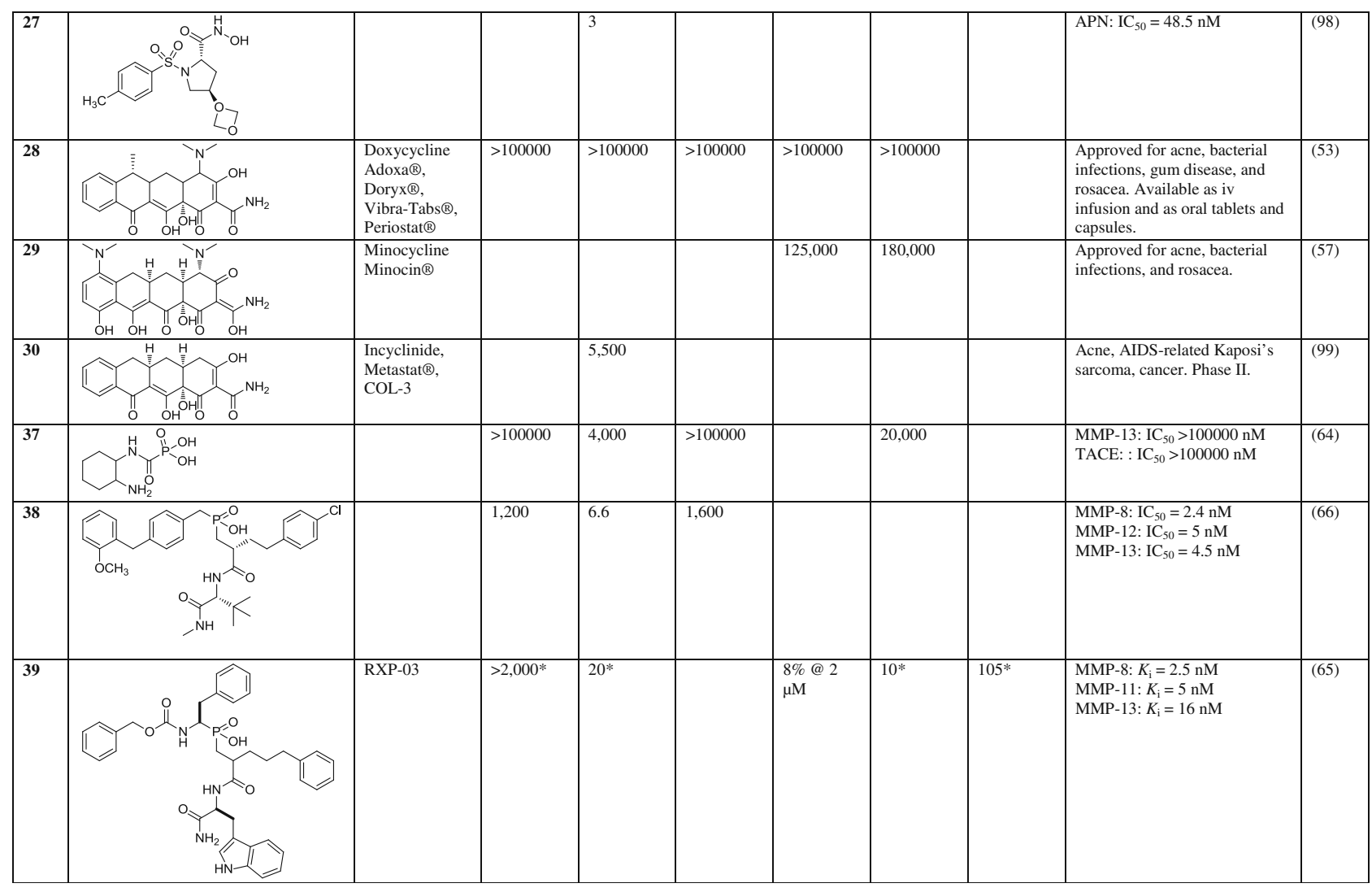

Values with asterisk $(*)$ means $\mathrm{K}_{\mathrm{i}}$

use. Alternatively, early specific gelatinase inhibitors may prevent the development of pain. The fact remains that there have been no studies of the role of gelatinases in neuropathic pain after SCI. The debilitating nature of neuropathic pain after SCI and the potential of MMP-9 and MMP-2 to alter the course of its development and maintenance places greater emphasis on explorative studies of selective gelatinase inhibitors.

\section{SYNTHETIC GELATINASE INHIBITORS}

Gelatinase has been implicated in a variety of pathological processes and diseases, including inflammation, cardiovascular disease, infection, neurodegenerative disease, immune response, cancer cell invasion, and metastasis $[2,8,49]$. Thus, selective gelatinase inhibitors are highly sought. However, due to the structural similarities of
MMPs, selective inhibition of gelatinase has been challenging. As recent reviews of MMP inhibitors are available [50-52], this section will focus on gelatinase inhibitors.

\section{Competitive inhibitors}

The first-generation MMP inhibitors were broadspectrum peptidomimetics, containing a hydroxamate moiety that chelated the catalytic zinc and inactivated the protein. Examples of early peptidomimetics are batimastat (1), marimastat (2), and ilomastat (3) (Table 3). Although these small molecules inhibited MMPs at nanomolar concentrations, they were not selective, and in many cases also inhibited the a disintegrin and metalloproteinase ADAMs (tumor necrosis factor alpha converting enzyme TACE) proteases. Moreover, the hydroxamate moiety is readily metabolized [51], contributing to the poor oral bioavailability and limited in vivo

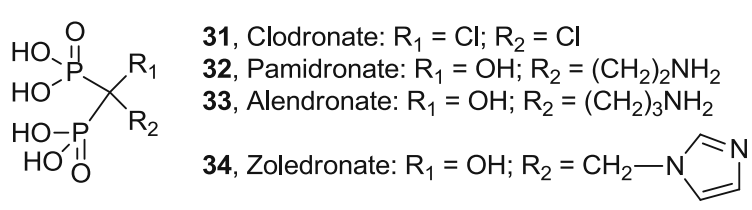

FIG. 1. Phosphorus-based inhibitors.

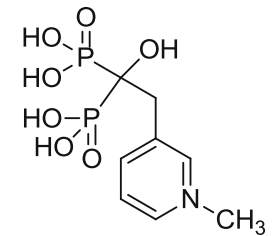

35, NE-10244<smiles>O=P(O)(O)C(O)(Cc1cccnc1)P(=O)(O)O</smiles>

36, NE-58051 
Table 4. Mechanism-based MMP Inhibitors.

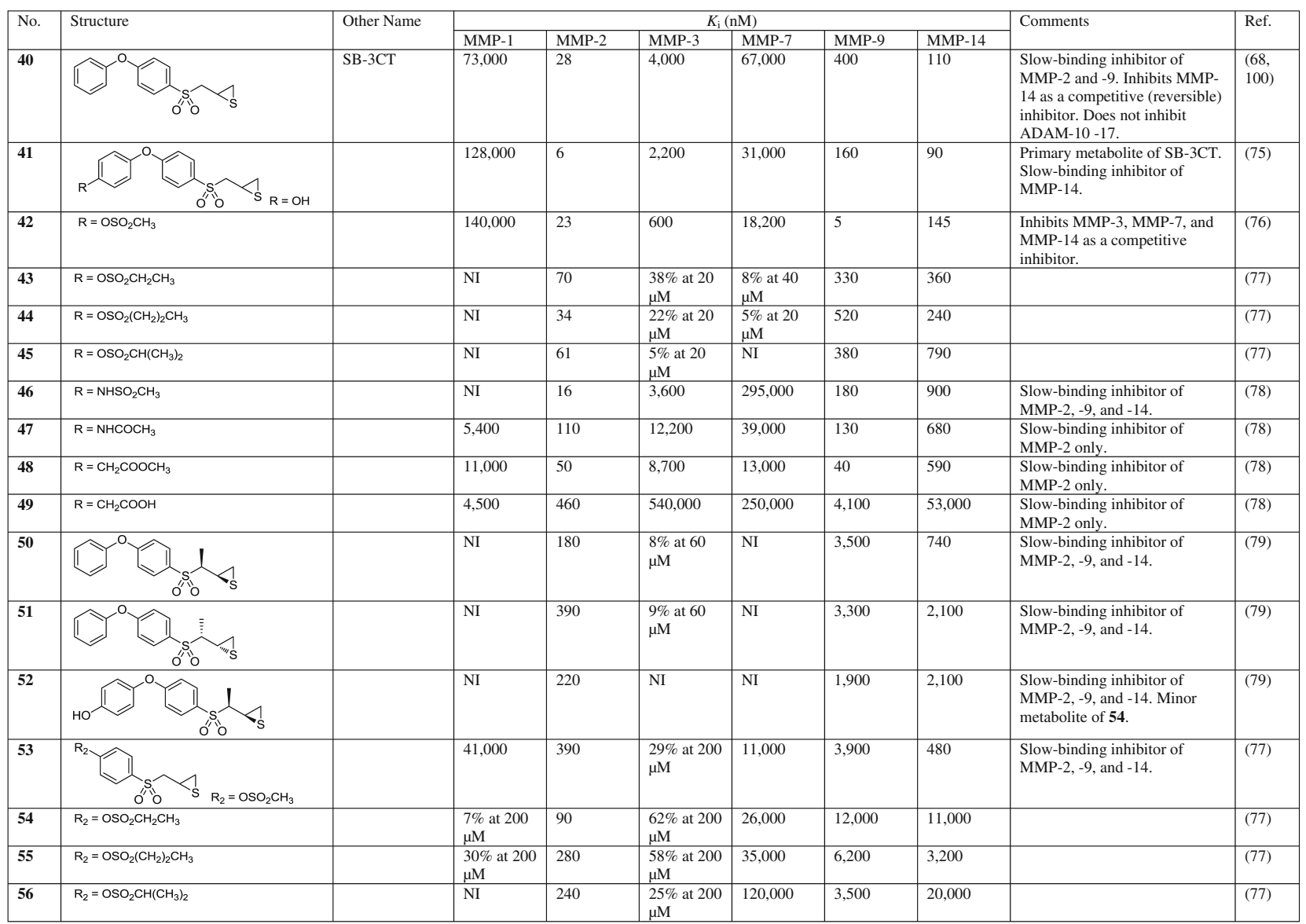

$\mathrm{NI}=$ non inhibitory

efficacy. Another drawback is that these broad-spectrum inhibitors produced musculoskeletal syndrome [53].

Other zinc-binding groups have been used. Rebimastat (BMS-275291, 4) contains a mercaptoacyl as a zincbinding group and tanomastat (BAY 12-9566, 5) has a zinc-binding carboxylate group. More selective MMP inhibitors have been developed, such as prinomastat (6) [54] and cipemastat (7) [55]. Examples of additional peptidomimetic and nonpeptidomimetic competitive inhibitors are listed in Table 3. However, as zinc chelators these inhibitors target the gelatinases, as well as other zinc-dependent enzymes, including other MMPs.
Since their discovery in the 1950s, tetracyclines have been widely used for their antimicrobial properties. However, tetracyclines also have nonantimicrobial properties, and among them is the ability to inhibit MMPs [56]. Doxycycline $\left(\right.$ Periostat $^{\circledR}, 28$ ) is the only drug approved as an MMP inhibitor for the treatment of periodontitis. Minocycline (29) is a second-generation tetracycline analog with weak broad-spectrum MMP inhibitory activity [57] approved for acne, bacterial infections, and rosacea. Minocycline has been reported to have neuroprotective effects in various animal models of neurological diseases [58,59]. Incyclinide (Metastat ${ }^{\circledR}$,

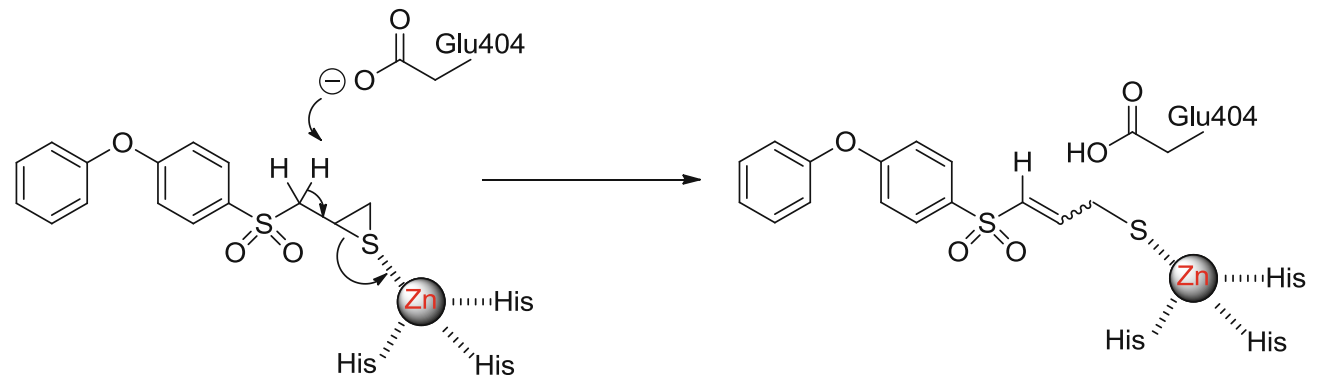

FIG. 2. Mechanism of gelatinase inhibition by SB-3CT. 
COL3 (30)) is a second-generation chemically modified tetracycline that lacks antimicrobial properties, inhibiting collagenases (MMP-1, MMP-8, and MMP-13), gelatinases (MMP-2 and MMP-9), and MT1-MMP, as well as other MMPs [60].

Bisphosphonates are potent inhibitors of osteoclastic activity and are widely used clinically for arresting or preventing bone loss associated with osteoporosis, metastatic bone disease, and other bone fragility conditions. Bisphosphonates also inhibit various MMPs [61, 62]. Clodronate (31), pamidronate (32), alendronate (33), and zoledronate (34), inhibit MMP-1, MMP-2, MMP-3, MMP7, MMP-8, MMP-9, MMP-12, MMP-13, and MMP-14, with $\mathrm{IC}_{50} \mathrm{~s}$ ranging from 50 to $150 \mu \mathrm{M}$. Analogs of risedronate, NE-10244 (35), and NE-58051 (36) (refer to FIG. 1 for their structures), inhibit MMP-2, MMP-9, and MMP-12, with $\mathrm{IC}_{50} \mathrm{~S}$ of 40,160 , and $80 \mu \mathrm{M}$, respectively [63]. Carbamoylphosphonates (37) [64] and phosphinates $(38,39)$ have been reported $[65,66]$ as MMP inhibitors.

\section{Mechanism-based inhibitors}

In 2000, Brown et al. [67] reported on the design and synthesis of SB-3CT (40) (Table 4), the first mechanismbased inhibitor for gelatinases. In mechanism-based or slow-binding inhibition, the inhibitor-enzyme complex undergoes a requisite conformational change that does not readily reverse. SB-3CT is selective for MMP-2 and MMP-9, does not inhibit other MMPs, and inhibits MMP-14 (MT1-MMP) as a simple competitive (reversible) inhibitor [68]. Although the biphenyl ether motif is reminiscent of other MMP inhibitors, the basis for MMP inhibition by SB-3CT is mechanistically unique and different from all other reported MMP inhibitors. This is due to the ability of gelatinases to facilitate the requisite rate-limiting deprotonation event leading to thiirane-ring opening with the active-site zinc ion (FIG. 2) [69]. Because the reactive thiolate is only generated within the active site of gelatinases, indiscriminate inhibition of other MMPs does not exist. SB-3CT has shown efficacy in several animal models of disease, including stroke [70], vascular permeability [71], vascular remodeling [72], subarachnoid hemorrhage [73], cardiopulmonary resuscitation [74], and SCI [6].

Although SB-3CT has demonstrated efficacy, it is rapidly and extensively metabolized by hydroxylation at the terminal phenyl ring (41) [75] to a more potent gelatinase inhibitor than the parent SB-3CT. The sulfonate (42) was designed to block the primary site of metabolism of SB-3CT [76]. Additional sulfonates (4345) are slow-binding selective gelatinase inhibitors [77]. Other groups have been introduced into the terminal phenyl ring of SB-3CT to block metabolism, including $\mathrm{N}$-methanesulfonate (46), $\mathrm{N}$-acetate (47), methyl acetate (48), and methyl acetic acid (49) [78]. In efforts to reduce metabolism at the $\alpha$-position to the sulfonyl group in SB-
3CT, 4 methyl diasteromers were prepared [79]. Of these, $\mathbf{5 0}$ and $\mathbf{5 1}$ were active slow-binding inhibitors of MMP2, MMP-9, and MMP-14. The p-hydroxy methyl derivative $\mathbf{5 2}$ had a similar inhibition profile as $\mathbf{5 0}$. To increase water solubility and metabolic stability, sulfonates 53-56 were prepared in which the terminal phenyl ring was eliminated [77]; these compounds showed potent inhibition of MMP-2 only.

\section{CONCLUSIONS AND FUTURE STUDIES}

It has become clear that MMPs have differing roles in both pathogenesis and recovery after SCI. How they influence injury and recovery processes is dependent on a number of factors that include when and where they are expressed and the profile of available substrates. As such, specific gelatinase inhibitors, targeting specific cellular and temporal profiles, may be more efficacious than their broad-spectrum counterparts. The potential to regulate neuropathic pain after SCI through gelatinase inhibition warrants detailed examination. Although studies of SCI support the view that early gelatinase activity is detrimental, in part, by promoting barrier dysfunction and early inflammation, involvement of MMPs in the more chronically injured cord is more complex. During wound healing, gelatinases modulate the formation of an inhibitory glial scar, support axonal regeneration, promote cell survival, and attenuate mechanical allodynia. Thus, the application of broad-spectrum MMP inhibitors in the more chronically injured cord should be approached with caution because any benefit may be outweighed by untoward effects.

Acknowledgments: This research was supported by the National Institutes of Health/National Institute of Neurological Disorders and Stroke/National Cancer Institute (grant numbers: RO1NS050159, R21NS065937, RO1NS039278, RO1CA122417, and RC1NS068200). Full conflict of interest disclosure is available in the electronic supplementary material for this article.

Open Access This article is distributed under the terms of the Creative Commons Attribution Noncommercial License which permits any noncommercial use, distribution, and reproduction in any medium, provided the original author(s) and source are credited.

\section{REFERENCES}

1. Page-McCaw A, Ewald AJ, Werb Z. Matrix metalloproteinases and the regulation of tissue remodelling. Nat Rev Mol Cell Biol 2007;8:221-233.

2. Yong VW. Metalloproteinases: mediators of pathology and regeneration in the CNS. Nat Rev Neurosci 2005;6:931-944.

3. Yong VW, Agrawal SM, Stirling DP. Targeting MMPs in acute and chronic neurological conditions. Neurotherapeutics 2007;4:580-589. 
4. Zhang H, Adwanikar H, Werb Z, Noble-Haeusslein LJ. Matrix metalloproteinases and neurotrauma: evolving roles in injury and reparative processes. Neuroscientist 2010;16:156-170.

5. Noble LJ, Donovan F, Igarashi T, Goussev S, Werb Z. Matrix metalloproteinases limit functional recovery after spinal cord injury by modulation of early vascular events. J Neurosci 2002;22:75267535 .

6. Yu F, Kamada H, Niizuma K, Endo H, Chan PH. Induction of mmp-9 expression and endothelial injury by oxidative stress after spinal cord injury. J Neurotrauma 2008;25:184-195.

7. Rosell A, Lo EH. Multiphasic roles for matrix metalloproteinases after stroke. Curr Opin Pharmacol 2008;8:82-89.

8. Agrawal SM, Lau L, Yong VW. MMPs in the central nervous system: where the good guys go bad. Semin Cell Dev Biol 2008;19:42-51.

9. Sternlicht MD, Werb Z. How matrix metalloproteinases regulate cell behavior. Annu Rev Cell Dev Biol 2001;17:463-516.

10. Imai K, Yokohama Y, Nakanishi I, et al. Matrix metalloproteinase 7 [matrilysin] from human rectal carcinoma cells. Activation of the precursor, interaction with other matrix metalloproteinases and enzymic properties. J Biol Chem 1995;270:6691-6697.

11. Knauper V, Bailey L, Worley JR, Soloway P, Patterson ML, Murphy G. Cellular activation of proMMP-13 by MT1-MMP depends on the C-terminal domain of MMP-13. FEBS Lett 2002;532:127-130.

12. Cowell S, Knauper V, Stewart ML, et al. Induction of matrix metalloproteinase activation cascades based on membrane-type 1 matrix metalloproteinase: associated activation of gelatinase A, gelatinase B and collagenase 3. Biochem J 1998;331(pt 2):453-458.

13. Crocker SJ, Pagenstecher A, Campbell IL. The TIMPs tango with MMPs and more in the central nervous system. J Neurosci Res 2004;75:1-11.

14. de Castro RC Jr., Burns CL, McAdoo DJ, Romanic AM. Metalloproteinase increases in the injured rat spinal cord. Neuroreport 2000;11:3551-3554.

15. Duchossoy Y, Horvat JC, Stettler O. MMP-related gelatinase activity is strongly induced in scar tissue of injured adult spinal cord and forms pathways for ingrowing neurites. Mol Cell Neurosci 2001;17:945-956.

16. Goussev S, Hsu JY, Lin Y, et al. Differential temporal expression of matrix metalloproteinases after spinal cord injury: relationship to revascularization and wound healing. J Neurosurg 2003;99:188-197.

17. Hsu JY, McKeon R, Goussev S, et al. Matrix metalloproteinase-2 facilitates wound healing events that promote functional recovery after spinal cord injury. J Neurosci 2006;26:9841-9850.

18. $\mathrm{Xu} \mathrm{J,} \mathrm{Kim} \mathrm{GM,} \mathrm{Ahmed} \mathrm{SH,} \mathrm{Yan} \mathrm{P,} \mathrm{Xu} \mathrm{XM,} \mathrm{Hsu} \mathrm{CY.}$ Glucocorticoid receptor-mediated suppression of activator protein1 activation and matrix metalloproteinase expression after spinal cord injury. J Neurosci 2001;21:92-97.

19. Wells JE, Rice TK, Nuttall RK, et al. An adverse role for matrix metalloproteinase 12 after spinal cord injury in mice. J Neurosci 2003;23:10107-10115.

20. Veeravalli KK, Dasari VR, Tsung AJ, et al. Human umbilical cord blood stem cells upregulate matrix metalloproteinase- 2 in rats after spinal cord injury. Neurobiol Dis 2009;36:200-212.

21. Yang Y, Estrada EY, Thompson JF, Liu W, Rosenberg GA. Matrix metalloproteinase-mediated disruption of tight junction proteins in cerebral vessels is reversed by synthetic matrix metalloproteinase inhibitor in focal ischemia in rat. J Cereb Blood Flow Metab 2007;27:697-709.

22. Buhler LA, Samara R, Guzman E, et al. Matrix metalloproteinase-7 facilitates immune access to the CNS in experimental autoimmune encephalomyelitis. BMC Neurosci 2009;10:17.

23. Asahi M, Wang X, Mori $T$, et al. Effects of matrix metalloproteinase-9 gene knock-out on the proteolysis of blood-brain barrier and white matter components after cerebral ischemia. J Neurosci 2001;21:7724-7732.

24. Caron A, Desrosiers RR, Beliveau R. Ischemia injury alters endothelial cell properties of kidney cortex: stimulation of MMP9. Exp Cell Res 2005;310:105-116.

25. Rosenberg GA, Yang Y. Vasogenic edema due to tight junction disruption by matrix metalloproteinases in cerebral ischemia. Neurosurg Focus 2007;22:E4.
26. Reijerkerk A, Kooij G, van der Pol SM, Khazen S, Dijkstra CD, de Vries HE. Diapedesis of monocytes is associated with MMPmediated occludin disappearance in brain endothelial cells. FASEB J 2006;20:2550-2552.

27. Whetstone WD, Hsu JY, Eisenberg M, Werb Z, Noble-Haeusslein LJ. Blood-spinal cord barrier after spinal cord injury: relation to revascularization and wound healing. J Neurosci Res 2003;74:227-239.

28. Shipley JM, Wesselschmidt RL, Kobayashi DK, Ley TJ, Shapiro $\mathrm{SD}$. Metalloelastase is required for macrophage-mediated proteolysis and matrix invasion in mice. Proc Natl Acad Sci U S A 1996;93:3942-3946.

29. Haorah J, Ramirez SH, Schall K, Smith D, Pandya R, Persidsky Y. Oxidative stress activates protein tyrosine kinase and matrix metalloproteinases leading to blood-brain barrier dysfunction. J Neurochem 2007;101:566-576.

30. Alexander JS, Elrod JW. Extracellular matrix, junctional integrity and matrix metalloproteinase interactions in endothelial permeability regulation. J Anat 2002;200:561-574.

31. Sugawara T, Lewen A, Gasche Y, Yu F, Chan PH. Overexpression of SOD1 protects vulnerable motor neurons after spinal cord injury by attenuating mitochondrial cytochrome $\mathrm{c}$ release. FASEB J 2002;16:1997-1999.

32. Dang AB, Tay BK, Kim HT, Nauth A, Alfonso-Jaume MA, Lovett DH. Inhibition of MMP2/MMP9 after spinal cord trauma reduces apoptosis. Spine [Phila Pa 1976] 2008;33:E576-579.

33. Trivedi A, Hsu CY, Lin Y, et al. The effects of acute and extended inhibition of matrix metalloproteinases on demyelination and functional recovery after spinal cord injury. Int $\mathrm{J}$ Neuroprotect Neuroregen 2005;2:30-38.

34. Pizzi MA, Crowe MJ. Matrix metalloproteinases and proteoglycans in axonal regeneration. Exp Neurol 2007;204:496-511.

35. Silver J, Miller JH. Regeneration beyond the glial scar. Nat Rev Neurosci 2004;5:146-156.

36. Jones LL, Yamaguchi Y, Stallcup WB, Tuszynski MH. NG2 is a major chondroitin sulfate proteoglycan produced after spinal cord injury and is expressed by macrophages and oligodendrocyte progenitors. J Neurosci 2002;22:2792-2803.

37. Bradbury EJ, Moon LD, Popat RJ, et al. Chondroitinase ABC promotes functional recovery after spinal cord injury. Nature 2002;416:636-640.

38. Hsu JY, Bourguignon LY, Adams CM, et al. Matrix metalloproteinase-9 facilitates glial scar formation in the injured spinal cord. J Neurosci 2008;28:13467-13477.

39. Busch SA, Horn KP, Silver DJ, Silver J. Overcoming macrophagemediated axonal dieback following CNS injury. J Neurosci 2009;29:9967-9976.

40. Yong VW, Power C, Forsyth P, Edwards DR. Metalloproteinases in biology and pathology of the nervous system. Nat Rev Neurosci 2001;2:502-511.

41. Siddall PJ, McClelland JM, Rutkowski SB, Cousins MJ. A longitudinal study of the prevalence and characteristics of pain in the first 5 years following spinal cord injury. Pain 2003;103:249257.

42. Detloff MR, Fisher LC, McGaughy V, Longbrake EE, Popovich PG, Basso DM. Remote activation of microglia and pro-inflammatory cytokines predict the onset and severity of below-level neuropathic pain after spinal cord injury in rats. Exp Neurol 2008;212:337-347.

43. Kawasaki Y, Xu ZZ, Wang X, et al. Distinct roles of matrix metalloproteases in the early- and late-phase development of neuropathic pain. Nat Med 2008;14:331-336.

44. Kobayashi H, Chattopadhyay S, Kato K, et al. MMPs initiate Schwann cell-mediated MBP degradation and mechanical nociception after nerve damage. Mol Cell Neurosci 2008;39:619-627.

45. Chattopadhyay S, Myers RR, Janes J, Shubayev V. Cytokine regulation of MMP-9 in peripheral glia: implications for pathological processes and pain in injured nerve. Brain Behav Immun 2007;21:561-568

46. Chandler S, Coates R, Gearing A, Lury J, Wells G, Bone E. Matrix metalloproteinases degrade myelin basic protein. Neurosci Lett 1995;201:223-226.

47. Devor M. Sodium channels and mechanisms of neuropathic pain. J Pain 2006;7:S3-S12. 
48. Schafers M, Sorkin L. Effect of cytokines on neuronal excitability. Neurosci Lett 2008;437:188-193.

49. Overall CM, Kleifeld O. Tumour microenvironment - opinion: validating matrix metalloproteinases as drug targets and anti-targets for cancer therapy. Nat Rev Cancer 2006;6:227-239.

50. Fisher JF, Mobashery S. Recent advances in MMP inhibitor design. Cancer Metastasis Rev 2006;25:115-136.

51. Jacobsen JA, Major Jourden JL, Miller MT, Cohen SM. To bind zinc or not to bind zinc: an examination of innovative approaches to improved metalloproteinase inhibition. Biochim Biophys Acta 2010;1803:72-94.

52. Dorman G, Cseh S, Hajdu I, et al. Matrix metalloproteinase inhibitors: a critical appraisal of design principles and proposed therapeutic utility. Drugs 2010;70:949-964.

53. Peterson JT. Matrix metalloproteinase inhibitor development and the remodeling of drug discovery. Heart Fail Rev 2004;9:63-79.

54. Wada CK, Holms JH, Curtin ML, et al. Phenoxyphenyl sulfone Nformylhydroxylamines [retrohydroxamates] as potent, selective, orally bioavailable matrix metalloproteinase inhibitors. J Med Chem 2002;45:219-232.

55. Ishikawa T, Nishigaki F, Miyata $\mathrm{S}$, et al. Prevention of progressive joint destruction in collagen-induced arthritis in rats by a novel matrix metalloproteinase inhibitor, FR255031. Br J Pharmacol 2005;144:133-143.

56. Sapadin AN, Fleischmajer R. Tetracyclines: nonantibiotic properties and their clinical implications. J Am Acad Dermatol 2006;54:258-265.

57. Romero-Perez D, Fricovsky E, Yamasaki KG, et al. Cardiac uptake of minocycline and mechanisms for in vivo cardioprotection. J Am Coll Cardiol 2008;52:1086-1094.

58. Yong VW, Wells J, Giuliani F, Casha S, Power C, Metz LM. The promise of minocycline in neurology. Lancet Neurol 2004;3:744 751.

59. Kim HS, Suh YH. Minocycline and neurodegenerative diseases. Behav Brain Res 2009;196:168-179.

60. Lee HM, Golub LM, Cao J, et al. CMT-3, a non-antimicrobial tetracycline [TC], inhibits MT1-MMP activity: relevance to cancer. Curr Med Chem 2001;8:257-260.

61. Teronen O, Heikkila P, Konttinen YT, et al. MMP inhibition and downregulation by bisphosphonates. Ann N Y Acad Sci 1999;878:453-465.

62. Heikkila P, Teronen O, Moilanen M, et al. Bisphosphonates inhibit stromelysin-1 [MMP-3], matrix metalloelastase [MMP-12], collagenase-3 [MMP-13] and enamelysin [MMP-20], but not urokinasetype plasminogen activator, and diminish invasion and migration of human malignant and endothelial cell lines. Anticancer Drugs 2002;13:245-254.

63. Boissier S, Ferreras M, Peyruchaud O, et al. Bisphosphonates inhibit breast and prostate carcinoma cell invasion, an early event in the formation of bone metastases. Cancer Res 2000;60:29492954.

64. Hoffman A, Qadri B, Frant J, et al. Carbamoylphosphonate matrix metalloproteinase inhibitors 6: cis-2-aminocyclohexylcarbamoylphosphonic acid, a novel orally active antimetastatic matrix metalloproteinase-2 selective inhibitor-synthesis and pharmacodynamic and pharmacokinetic analysis. J Med Chem 2008;51:1406-1414.

65. Matziari M, Beau F, Cuniasse P, Dive V, Yiotakis A. Evaluation of P1'-diversified phosphinic peptides leads to the development of highly selective inhibitors of MMP-11. J Med Chem 2004;47:325336.

66. Reiter LA, Mitchell PG, Martinelli GJ, Lopresti-Morrow LL, Yocum SA, Eskra JD. Phosphinic acid-based MMP-13 inhibitors that spare MMP-1 and MMP-3. Bioorg Med Chem Lett 2003;13:2331-2336

67. Brown S, Bernardo MM, Li ZH, et al. Potent and selective mechanism-based inhibition of gelatinases. J Am Chem Soc 2000;122:6799-6800.

68. Toth M, Bernardo MM, Gervasi DC, et al. Tissue inhibitor of metalloproteinase [TIMP]-2 acts synergistically with synthetic matrix metalloproteinase [MMP] inhibitors but not with TIMP-4 to enhance the [membrane type 1]-MMP-dependent activation of pro-MMP-2. J Biol Chem 2000;275:41415-41423.
69. Forbes C, Shi Q, Fisher JF, et al. Active site ring-opening of a thiirane moiety and picomolar inhibition of gelatinases. Chem Biol Drug Des 2009;74:527-534.

70. Gu Z, Cui J, Brown S, et al. A highly specific inhibitor of matrix metalloproteinase-9 rescues laminin from proteolysis and neurons from apoptosis in transient focal cerebral ischemia. J Neurosci 2005;25:6401-6408.

71. Luplertlop N, Misse D, Bray D, et al. Dengue-virus-infected dendritic cells trigger vascular leakage through metalloproteinase overproduction. EMBO Rep 2006;7:1176-1181.

72. Ota R, Kurihara C, Tsou TL, et al. Roles of matrix metalloproteinases in flow-induced outward vascular remodeling. J Cereb Blood Flow Metab 2009;29:1547-1558.

73. Guo Z, Sun X, He Z, Jiang Y, Zhang X, Zhang JH. Matrix metalloproteinase- 9 potentiates early brain injury after subarachnoid hemorrhage. Neurol Res 2010;32:715-720

74. He ZJ, Huang ZT, Chen XT, Zou ZJ. Effects of matrix metalloproteinase 9 inhibition on the blood brain barrier and inflammation in rats following cardiopulmonary resuscitation. Chin Med J [Engl] 2009;122:2346-2351.

75. Lee M, Villegas-Estrada A, Celenza G, et al. Metabolism of a highly selective gelatinase inhibitor generates active metabolite. Chem Biol Drug Des 2007;70:371-382.

76. Lee M, Celenza G, Boggess B, et al. A potent gelatinase inhibitor with anti-tumor-invasive activity and its metabolic disposition. Chem Biol Drug Des 2009;73:189-202.

77. Testero SA, Lee M, Staran R, et al. Sulfonate-containing thiiranes as selective gelatinase inhibitors. Med Chem Lett 2011;2:177-181.

78. Ikejiri M, Bernardo MM, Meroueh SO, et al. Design, synthesis, and evaluation of a mechanism-based inhibitor for gelatinase A. J Org Chem 2005;70:5709-5712.

79. Gooyit M, Lee M, Hesek D, et al. Synthesis, kinetic characterization and metabolism of diastereomeric 2-[1-[4-phenoxyphenylsulfonyl]ethyl]thiiranes as potent gelatinase and MT1-MMP inhibitors. Chem Biol Drug Des 2009;74:535-546.

80. Botos I, Scapozza L, Zhang D, Liotta LA, Meyer EF. Batimastat, a potent matrix mealloproteinase inhibitor, exhibits an unexpected mode of binding. Proc Natl Acad Sci U S A 1996;93:2749-2754.

81. Grobelny D, Poncz L, Galardy RE. Inhibition of human skin fibroblast collagenase, thermolysin, and Pseudomonas aeruginosa elastase by peptide hydroxamic acids. Biochemistry 1992;31:7152-7154.

82. Naglich JG, Jure-Kunkel M, Gupta E, et al. Inhibition of angiogenesis and metastasis in two murine models by the matrix metalloproteinase inhibitor, BMS-275291. Cancer Res 2001;61:8480-8485.

83. Gatto C, Rieppi M, Borsotti P, et al. BAY 12-9566, a novel inhibitor of matrix metalloproteinases with antiangiogenic activity. Clin Cancer Res 1999;5:3603-3607.

84. Aranapakam V, Grosu GT, Davis JM, et al. Synthesis and structureactivity relationship of alpha-sulfonylhydroxamic acids as novel, orally active matrix metalloproteinase inhibitors for the treatment of osteoarthritis. J Med Chem 2003;46:2361-2375.

85. Tamura Y, Watanabe F, Nakatani T, et al. Highly selective and orally active inhibitors of type IV collagenase [MMP-9 and MMP-2]: Nsulfonylamino acid derivatives. J Med Chem 1998;41:640-649.

86. Aoki T, Kataoka H, Morimoto M, Nozaki K, Hashimoto N. Macrophage-derived matrix metalloproteinase- 2 and -9 promote the progression of cerebral aneurysms in rats. Stroke 2007;38:162-169.

87. Becker DP, Barta TE, Bedell LJ, et al. Orally active MMP-1 sparing alpha-tetrahydropyranyl and alpha-piperidinyl sulfone matrix metalloproteinase [MMP] inhibitors with efficacy in cancer, arthritis, and cardiovascular disease. J Med Chem 2010;53:6653-6680.

88. Kolodziej SA, Hockerman SL, Boehm TL, et al. Orally bioavailable dual MMP-1/MMP-14 sparing, MMP-13 selective alphasulfone hydroxamates. Bioorg Med Chem Lett 2010;20:35573560 .

89. Nelson FC, Delos Santos E, Levin JI, et al. Benzodiazepine inhibitors of the MMPs and TACE. Bioorg Med Chem Lett 2002;12:2867-2870.

90. Yang SM, Scannevin RH, Wang B, et al. beta-N-Biaryl ether sulfonamide hydroxamates as potent gelatinase inhibitors: part 2 . Optimization of alpha-amino substituents. Bioorg Med Chem Lett 2008;18:1140-1145. 
91. Curtin ML, Florjancic AS, Heyman HR, et al. Discovery and characterization of the potent, selective and orally bioavailable MMP inhibitor ABT-770. Bioorg Med Chem Lett 2001;11:15571560.

92. Chung YJ, Lee KH, Park SH, Cho CW, Han MS. 5-carboxylate substituted piperazine-2-ones as potent and selective MMP-2 inhibitors. Bull Korean Chem Soc 2008;29:1103-1104.

93. Maquoi E, Sounni NE, Devy L, et al. Anti-invasive, antitumoral, and antiangiogenic efficacy of a pyrimidine-2,4,6-trione derivative, an orally active and selective matrix metalloproteinases inhibitor. Clin Cancer Res 2004;10:4038-4047.

94. Kim SH, Pudzianowski AT, Leavitt KJ, et al. Structure-based design of potent and selective inhibitors of collagenase-3 [MMP13]. Bioorg Med Chem Lett 2005;15:1101-1106.

95. Levin JI, Du MT, DiJoseph JF, et al. The discovery of anthranilic acid-based MMP inhibitors. Part 1: SAR of the 3-position. Bioorg Med Chem Lett 2001;11:235-238.
96. Levin JI, Gu Y, Nelson FC, et al. Heteroaryl and cycloalkyl sulfonamide hydroxamic acid inhibitors of matrix metalloproteinases. Bioorg Med Chem Lett 2001;11:239-242.

97. Zhang L, Zhang J, Fang H, Wang Q, Xu W. Design, synthesis and preliminary evaluation of new cinnamoyl pyrrolidine derivatives as potent gelatinase inhibitors. Bioorg Med Chem 2006;14:8286-8294

98. Cheng XC, Wang Q, Fang H, Tang W, Xu WF. Design, synthesis and evaluation of novel sulfonyl pyrrolidine derivatives as matrix metalloproteinase inhibitors. Bioorg Med Chem 2008;16:5398-5404.

99. Lokeshwar BL, Selzer MG, Zhu BQ, Block NL, Golub LM. Inhibition of cell proliferation, invasion, tumor growth and metastasis by an oral non-antimicrobial tetracycline analog [COL-3] in a metastatic prostate cancer model. Int J Cancer 2002;98:297-309.

100. Lee M, Bernardo MM, Meroueh SO, Brown S, Fridman R, Mobashery S. Synthesis of chiral 2-[4-phenoxyphenylsulfonylmethyl]thiiranes as selective gelatinase inhibitors. Org Lett 2005;7:4463-4465. 